\title{
DÜBLIN
}

Technological University Dublin

ARROW@TU Dublin

2015-09-04

\section{Wind Energy and Ireland: Could Forecasting Errors Lead to a Flawed Market?}

\author{
Michael McDonald \\ Technological University Dublin, michael.mcdonald@tudublin.ie \\ Thomas Woolmington \\ Technological University Dublin, thomas.woolmington@tudublin.ie \\ Keith Sunderland \\ Technological University Dublin, keith.sunderland@tudublin.ie
}

Follow this and additional works at: https://arrow.tudublin.ie/engscheleart

Part of the Electrical and Electronics Commons

\section{Recommended Citation}

McDonald, M., Woolington, T. \& Sunderland, K. (2015). Wind Energy and Ireland: Could forecasting errors lead to a flawed market? In: UPEC (ed.) 50th International Universities Power Engineering Conference (UPEC 2015). Staffordshire University, Stoke on Trent IEEE.

This Conference Paper is brought to you for free and open access by the School of Electrical and Electronic Engineering at ARROW@TU Dublin. It has been accepted for inclusion in Conference papers by an authorized administrator of ARROW@TU Dublin. For more information, please contact arrow.admin@tudublin.ie, aisling.coyne@tudublin.ie,gerard.connolly@tudublin.ie.

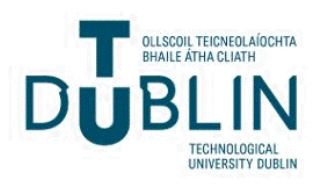




\section{Wind Energy and Ireland: Could forecasting errors lead to a flawed market?}

\author{
Michael McDonald \\ Dublin Institute of \\ Technology, Ireland \\ School of Electrical \\ \& Electronic Engineering \\ michael.mcdonald@dit.ie
}

\author{
Thomas Woolmington \\ Dublin Institute of \\ Technology, Ireland \\ School of Electrical \\ \& Electronic Engineering \\ thomas.woolmington@ dit.ie
}

\author{
Keith Sunderland \\ Dublin Institute of \\ Technology, Ireland \\ School of Electrical \\ \& Electronic Engineering \\ keith.sunderland@dit.ie
}

\begin{abstract}
This paper explores wind energy forecasting consistency by considering the error benchmarks associated with the generation output of a small wind farm in comparison to the national forecasting as provided by Eirgrid, the Irish TSO. This percentage error analysis will contrast the predicted (Eirgrid) capacity and actual wind energy output observations (Wind farm) and postulations that consider alternative prediction metrics are discussed. The findings suggest that in monthly like for like comparisons over a twelve month period, total MWh percentage errors of $\mathbf{- 0 . 3 6 \%}$ and $\mathbf{5 . 7 \%}$ are observed respectively for the actual generation and the forecasted prediction, when a monthly averaged window is considered. However if one considers higher frequency observations, such as those available through Eirgrid (15 minute periods), a mean absolute error of $28.5 \%$ is evident for the national wind generation capacity over the course of the same year. In the context of the proposed Irish wholesale and integrated single electricity market (I-SEM), an error of this magnitude could have severe financial implications for the wind energy sector; particularly if wind is to become the primary component of the future Irish energy mix.
\end{abstract}

Index Terms-- Wind Energy, Percentage Error, Forecasting

\section{INTRODUCTION}

Significant momentum is being sustained through global economic 'greening' and associated investment. In 2013, for the second year in a row, renewables accounted for almost half of new global power generation capacity; accounting for over $41 \%$ of new generating capacity globally and raising the share of renewables to $8.5 \%$ of the global electricity supply [1]. From an Irish perspective, there was $222 \mathrm{MW}$ of new wind generation capacity installed in 2014 delivering a total installed capacity of $2263 \mathrm{MW}$, enough to potentially displace over 2.3 million tonnes of $\mathrm{CO}_{2}$ when compared to traditional fossil fuels [2].

Wind energy, by its nature however, is intermittent and if grid stability is to be assured, it needs to be a constituent component of a wider generation mix. If an appropriate generation mix is to be optimised, where wind capacity is maximised for a transmission/distribution network, an accurate wind energy forecasting capability is required. In this regard, forecasting and validation of wind energy forecasts are essential for an optimised and sustainable wind energy portfolio. From a national renewable energy policy perspective, this consideration is especially important and relevant in the context of increased potential for installed capacity in the coming years in Ireland. Accurate wind energy forecasting will allow establishment of an appropriate generation mix prior to significant variations in the wind [3]. While wind energy as a renewable energy opportunity is mature with extensive research, knowledge and experience supporting its development, there is still no single forecasting method that encompasses all of the complexities associated with this natural resource [4]. That said, on one hand, less than completely accurate wind energy forecasts have been shown to reduce the overall integration costs for large scale development [5]. On the other and in the context of a redesigned wholesale Irish electricity market (I-SEM) [6], alignment with the European Electricity Target Model [7] is going to require wind generators to be as accurate as possible if they are to trade effectively.

The Irish wholesale electricity market (SEM), is a gross mandatory pool with a single system marginal price (SMP) in each period. Plants bid in the day-ahead market and are called to generate on a merit-order basis until the production is enough to service existing demand, after accounting for each plant's technical constraints [8]. The market came about in part due to requirements of the European Commission that electricity markets across Europe undergo a process of liberalisation and regulation [9]. However, this model for trading electricity has to comply with the European Union's (EU) Third Package. The Third Package prioritises the context for integrating Ireland in the internal EU market for electricity [10]. Furthermore, a transitional arrangement needs to reflect the fact that most EU wholesale electricity markets are self dispatch bilateral exchange models, in contrast to the mandatory pool central dispatch model of the SEM [10].

In September 2014, following consultation with market stakeholders, a high-level decision paper was published in respect of the proposed design of the new I-SEM [11]. The ISEM will be a forward market of financial trades only [8]. Moreover, it will be focused on liquid and transparent markets with an objective "to generate maximum competition through concentrating trading in the day ahead and intraday markets"[6]. The intraday market participants will make bids and offers to the market operator on a continuous basis. Feasible orders will be collected and submitted by the market operator and submitted to the Shared Order Book Function (SOBF), which is managed at the European level [10]. The Framework Guideline is based on the Target Electricity Model (the Target Model) which "is a high level description of the market mechanisms to facilitate" the EU internal market in electricity [10]. The current (SEM) market does not 
provide for an ex ante price (i.e. forecast in advance) nor does it permit widespread intraday trading. From late 2017 however, all market participants will be financially responsible for ensuring that their physical generation and demand is in balance with their contracted position traded in the day ahead and intraday markets. In other words, there is a strong financial imperative for energy producers to be able to better predict their output for the following day.

\section{METHODOLOGY}

The methodology used for this study aims to meet two main objectives. Firstly, analysis of the errors in relation to actual and predicted output of wind turbines, both at a 'local level', in which the focus is on a particular wind farm, and the accuracy of national TSO (Eirgrid) predictions are contrasted. Secondly, the work explores how determining possible future scenarios pertaining to wind energy in terms of forecasting errors may affect the wind energy sector.

\section{A. Data}

Two data sets are considered.

\section{1) Wind Farm ' $X$ ' $\left(W F_{x}\right)$}

$W F_{x}$ is a leading (private) international energy company that has a wind farm located in the West of Ireland. A non-disclosure agreement was required by the company so that they could remain anonymous (ensuring data protection in this regard). The data provided consisted of collated monthly generated (MWh) values over a 12 month period from February 2013 to January 2014. The dataset acquired consisted of the predicted and actual output in MWh for the site.

2) Eirgrid Forecasts for $W F_{x}\left(W P_{\text {TSO.. }}\right)$

To allow a detailed comparative study on a national level, data was also acquired from the national TSO $\left(X_{\text {Pred. }}\right)$, for the same time period of February 2013 to January 2014. Data from this source was acquired from a combination of values as published on their website and contact via email with Eirgrid Customer Support. The dataset on a national level consisted of MW values in fifteen minute time series records.

The analysis is performed in two stages. First, error in respect of the capacity of the wind farm $W F_{x}$ against TSO predictions over the year in question is considered. This error comparison is further contextualized in respect of the national wind generation capacity as predicted by the TSO $\left(W P_{T S O}\right)$ TSO. In this regard, various error statistics will be presented. Second, a longer term consideration is applied by considering the performance of the TSO $\left(W P_{T S O}\right)$, in how accurate predictions are over a five year period (February 2010February 2015).

\section{B. Prediction Error Statistics}

For the data sets considered here, the basic error percentage for delivered generation $(G)$ and/or demand $(D)$ with respect to what was predicted, is presented in (1) where the respective error is considered in terms of the delivered value.

$$
\operatorname{error}(\%)_{D \mid G}=\frac{\text { Delivered }_{D \mid G}-\text { Predicted }_{D \mid G}}{\text { Delivered }_{D \mid G}}
$$

The root-mean-square error (RMSE) and the mean absolute error (MAE) are dimensioned measures of average model performance error in that they both express prediction error in the units of the variable of interest. These can be are calculated using eqns. (2) and (3) respectively [12].

$$
\begin{aligned}
& \mathrm{MAE}=\frac{1}{n} \sum_{i=1}^{n}\left|e_{i}{ }^{2}\right| \\
& \mathrm{RMSE}=\sqrt{\frac{1}{n} \sum_{i=1}^{n} e_{i}^{2}}
\end{aligned}
$$

where there are $n$ samples of model errors , calculated as $\left(\mathrm{e}_{\mathrm{i}}\right.$, $\mathrm{i}=1,2, \ldots, n)$. The MAE is suitable to describe uniformly distributed errors, whereas in using RMSE, the errors are unbiased and follow a normal distribution [13].

\section{ANALYSIS AND RESULTS}

Fig. 1 illustrates the system wind generation against what was predicted by the TSO. Fig. 1 in this regard shows graphically the trend for planned versus actual wind energy production nationally. As one can see the monthly forecasting on a national level is relatively accurate overall. The largest percentage errors are found in the early and late months of the year where the actual wind energy production was less than the predicted output.

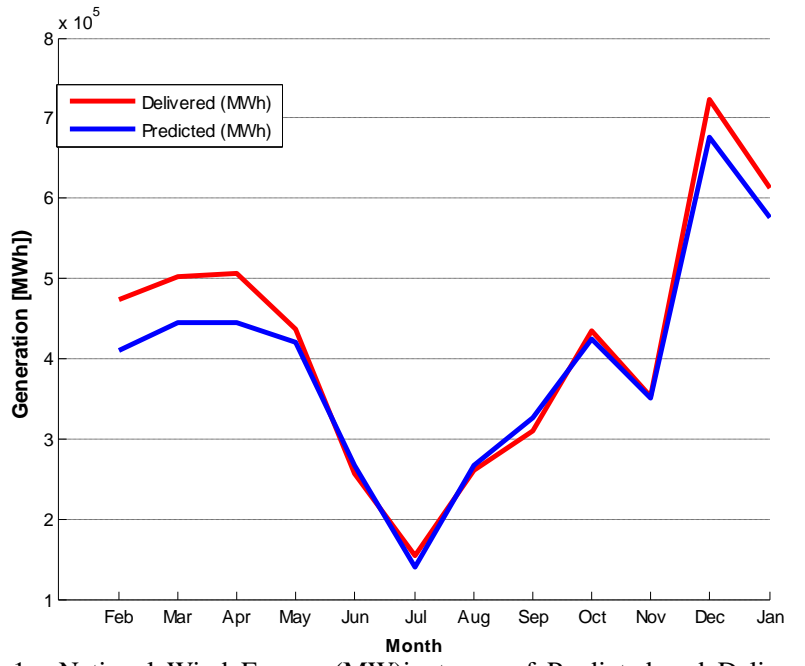

Fig. 1. National Wind Energy (MW)in terms of Predicted and Delivered Capacities

Looking at a system demand/capacity wind energy context, Fig. 2 (top) illustrates average monthly summaries for system demand/generation in terms of requirement/capacity (MW). In contrast, Fig. 2 (bottom) shows the (marginal) monthly contribution of the wind farm expressed in terms of overall system generation (MWh). The system/demand (MW) ratio illustrates that over the year in question, wind generation accounts for $18.2 \%$ on average of demand whereas the contribution from the wind farm is on average, just over $0.5 \%$ of the overall system generation capacity. 

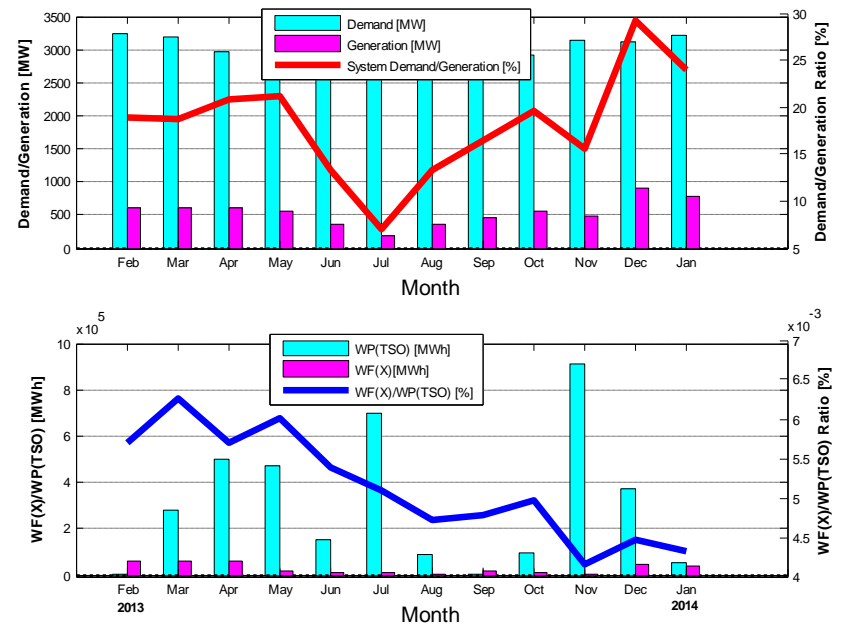

Fig. 2. Monthly System Demand (MW) and Generation Capacity (MW) expressed in terms of the Demand/Generation Ratio (Top) \& Monthly Wind farm (X) Generation (MWh) and System Generation (MWh) expressed in terms of a capacity ratio (MWh)

For the year being considered, the peak demand was (17/12/2013 @ 17:30) 4523MW, whereas the peak generation capacity on the system was 1769 (17/12/2013 @ 18:30). While at first glance, this looks promising, the contribution from the wind generation capacity nationally to system demands (MW), expressed as a ratio over this period (in terms of quarter-hour periods), ranged from $62 \%$ to $0.09 \%$.

A. WFx and $W P_{T S O}$ Capacity Predictions (1 year)

Looking first of all at the wind farm, Fig.3 summarises the monthly error variance in terms of the monthly wind farm produced/predicted (MWh) output.

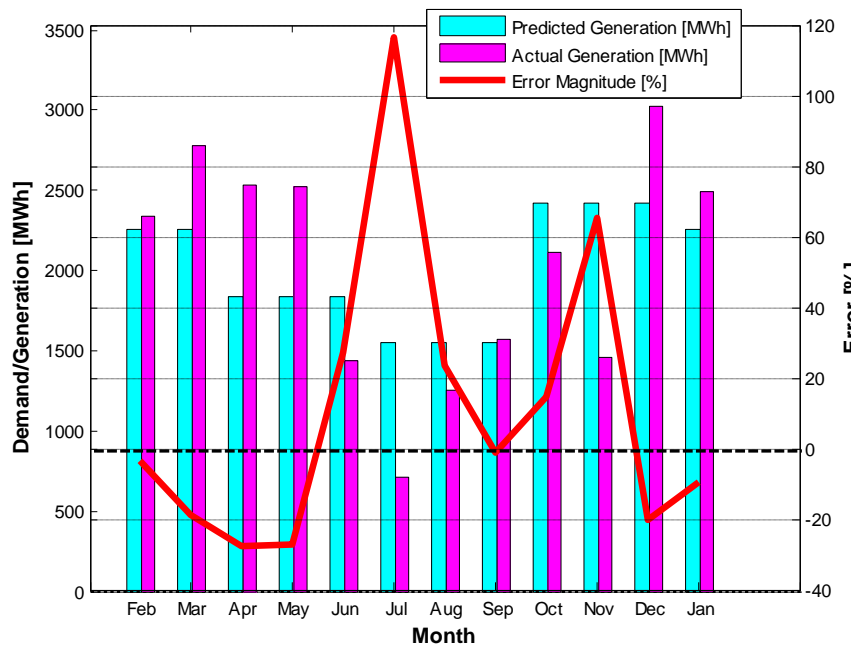

Frg!33. $W F_{x}$ : Predicted vs. Actual Production 2014

Comparing the wind farm situation to the national context, Table 1 illustrates monthly generation statistics for the wind farm $\left(W_{T x}\right)$ and generation capacity across the System $\left(W P_{T S O}\right)$. Also provided are error statistics. Monthly predictions for the wind farm are presented in terms of the actual generation output with a percentage error for each month and for the year are provided. Eirgrid's 15 minute data were collated to provide hourly and monthly average MW and MWh totals as well as providing a yearly total.

TABLE 1

AVERAGED MONTHLY SUMMARIES OF DEMAND/FORECAST COMPARISONS FOR $W F_{X}$ AND $W P_{T S O}$ IN TERMS OF RESPECTIVE ERROR STATISTICS

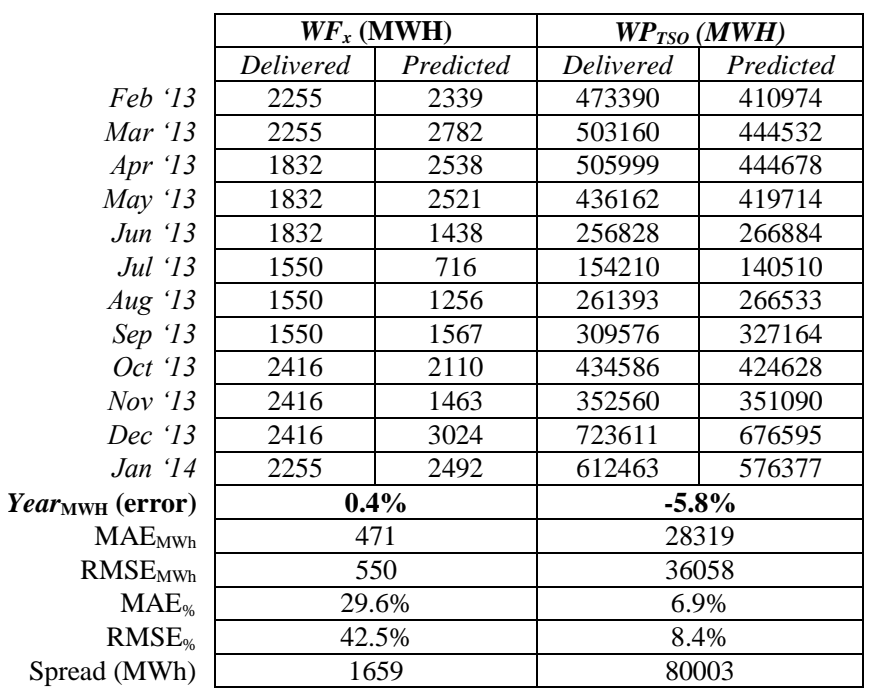

For the wind farm, September showed the lowest percentage error at $-1.1 \%$ (Table 1 ). Despite the significant monthly variances, a holistic error consideration over the 12 month period, yielded only a $0.36 \%$ percentage error (underestimated) for the year between forecasted and actual wind energy production. In the national context $\left(W P_{T S O}\right)$, February 2013 yielded the largest percentage error at $15.2 \%$ between predicted and actual output, where the output was underestimated, while November 2013 shows the most accurate forecasting with a percentage error of only $0.4 \%$ error observed. A holistic (annual) error consideration suggests an error of $5.8 \%$ (underestimated) for the national context.

While, the yearly error for both $W F_{x}$ and $W P_{T S O}$ initially look very favourable, it is important to point out however, that for both datasets the method of calculating the mean percentage error over monthly and yearly time series 'helps'

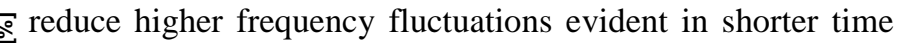
t steps and reduce overall percentage errors. The actual (provided) output value was used as a baseline to which the predicted output was statistically characterised. The large MAE and RMSE associated with $W F_{x}$ is explained by the anomaly in July when and error of $116.5 \%$ was observed. Furthermore, this anomalous month significantly influences the spread of error for the wind farm. In comparison to the system network, which has a $12 \%$ error spread when expressed in terms of maximum monthly generation capacity, whereas, the spread of the wind farm, for a similar comparison, is actually $52 \%$. A further point that should be made is in respect the validity of employing the RMSEs or the MAE for a sample $n=12$ [13]. Indeed, more can potentially be understood from the consideration of error values and variances themselves (e.g. such as in tables or in figures such as Fig. 2)[13].

When higher frequency observations are considered such as those presented in Table 2, a different scenario is presented. 
Table 2, presents monthly wind energy output (MW) in terms of TSO predictions. When monthly aggregates are considered, the errors are consistent with those presented for MWh in Table 1.

TABLE 2

DEMAND/FORECAST (MW) COMPARISONS FOR $W P_{\text {TSO IN TERMS OF }}$ RESPECTIVE ERROR STATISTICS

\begin{tabular}{|c|c|c|c|c|c|}
\hline \multirow{5}{*}{$\begin{array}{c}\text { Feb'13 } \\
\text { Mar '13 } \\
\text { Apr '13 }\end{array}$} & \multicolumn{2}{|c|}{$\begin{array}{c}\boldsymbol{W P}_{\mathrm{TSo}}(\boldsymbol{M W}) \\
\text { [Monthly Summaries] }\end{array}$} & \multirow{4}{*}{\multicolumn{2}{|c|}{ Error Statistics }} & \multirow{14}{*}{$\begin{array}{l}\text { MAE } \\
\text { RMSE } \\
\text { Spread }\end{array}$} \\
\hline & Delivered & Predicted & & & \\
\hline & 612 & 704 & & & \\
\hline & 599 & 678 & & & \\
\hline & 617 & 703 & Monthly & 1/4 hourly & \\
\hline May' '13 & 564 & 586 & $39 \mathrm{MW}$ & $89 \mathrm{MW}$ & \\
\hline Jun '13 & 371 & 357 & $12.8 \%$ & $28.5 \%$ & \\
\hline Jul'13 & 189 & 207 & $50 \mathrm{MW}$ & $126 \mathrm{MW}$ & \\
\hline Aug '13 & 358 & 351 & $18.1 \%$ & $57.5 \%$ & \\
\hline Sep '13 & 454 & 430 & \multicolumn{2}{|c|}{$1342 \mathrm{MW}$} & \\
\hline Oct'13 & 570 & 583 & & & \\
\hline Nov' '13 & 488 & 490 & & & \\
\hline Dec'13 & 910 & 973 & & & \\
\hline Jan' '14 & 775 & 823 & & & \\
\hline
\end{tabular}

However, the error statistics across both MAE and RMSE for quarter-hour considerations illustrate significant discrepancies. Indeed, the error spread is $76 \%$ when expressed in terms of the max demand (MW) for the period.

\section{B. $W P_{T S O}$ Capacity Predictions (5 year consideration)}

The preceding considerations highlight that the forecast datasets contain less overall variability over an extended period compared to real time fluctuations. The important point to take form this is that all of the time series values, for example the fifteen minute interval forecast, must be evaluated collectively, as no value itself gives a holistic overview of a generation system. Furthermore, governments, planners and developers take a much broader view of wind energy systems and inevitably look at output trends over very long periods, such as, twenty to twenty five year energy production.

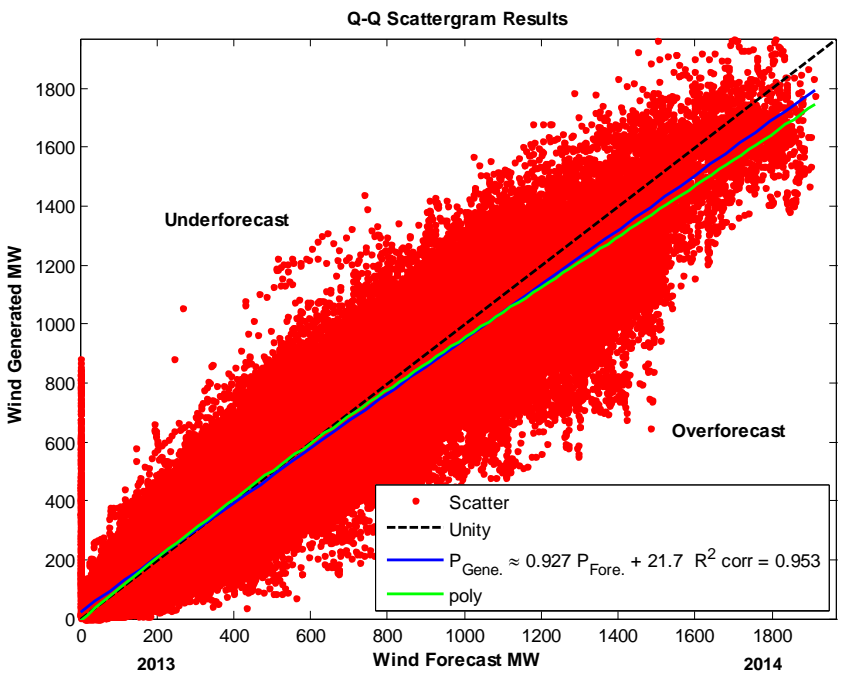

Fig. 4. 5-years Q-Q scattergram comparison of predicted vs. system provided wind generation (MW)
In relation to electrical systems planning and operational concerns, the shorter term forecasts are of greater concern due to traditional generation reserve requirements. In this regard, a 5-year study of predictions against actual demand (MW) delivered at system level was subsequently considered. Fig. 4 outlines the spread of forcaseted wind power in 15 minute bursts over a 5 year period. The spread of the scatter above and below the unity line gives an indication as to how inaccurate the model is. Furthermore the linear and polynomial regression identifies that that there is a tendancy to over-forcast during high power potential conditions (times when indicatively, high wind speeds are more prevalent).

The error histogram (MW) illustrated in top left of Fig. 5 appears symetrical. However there are a higher number of outliers in a positive error scenario (actual - forecastl). This symetry is somewhat distorted in a percentage error context (top right) due to the denominator size influencing the result, i.e. higher wind power (speed) records are presented as smaller percentage errors. The Absolute errors provide for unbiased presentations of the histograms.
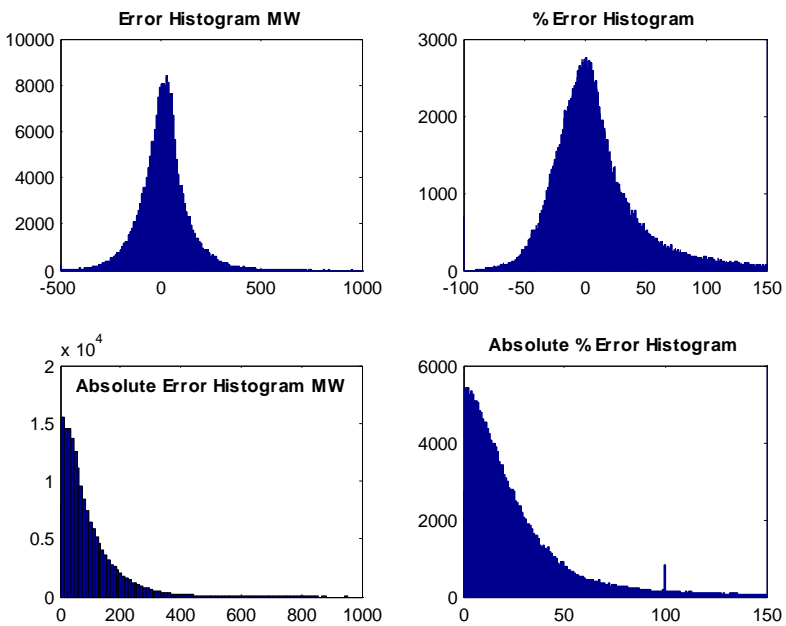

Fig. 5. Histogram analysis of the errors observed in predicted/delivered (MW) demand over the five year period on 15 minute data

CUSUM results as illustrated in Fig. 6 demonstrate a trend over time within the series.

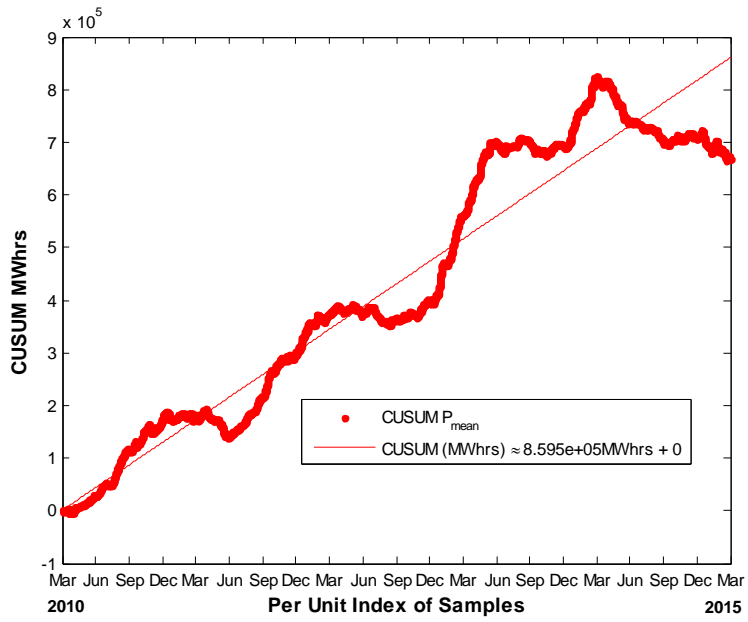

Fig. 6. CUSUM analysis of the errors observed in predicted/delivered (MW) demand over the five year period 
If the first three years are considered, the trend is somewhat cyclical (anually) in that the lowest point appears at circa june each year. This would be indicative of an overpredictive and underpredive cycle from winter to summer each year. It should also be pointed out that the hollistic wind generation system was growing at this time and as such, the errors could be construed as being biased (overly-large) as the system attempted to dispatch an increasingly evolving capacity. From 2014-15, the trend has levelled off indicating that the predictive model is more evenly biased relatively, i.e. cyclic swings in error appear to be stabilising.

\section{Error and System Marginal Price (SMP) Impact}

It is clear from the sample data that care must be taken as to what way error benchmarks are evaluated. Chai and Draxler in their argument against Bielecki in this regard ([13] and [5] respectively) emphasise this point. There are many arguments for and against different metrics to be used, for instance the $\% \mathrm{MAE}$ has a tendency to give very large errors at low output ranges which in this instance is not statistically significant to the system stability of the national grid. Furthermore there is also the added complexity as to the financial implications of the proposed new ex anti trading arrangement. In essence if a generator over predicts (under generates) it is likely to have a financial cost associated with it in either of the following forms.

(i) A financial penalty for breach of contracted generation capacity.

Or

(ii) The ability to buy the shortfall capacity on the intraday market.

While the first point is straight forward, it is worth remembering that the Irish market is currently approaching a $40 \%$ wind penetration [7] and as such the vast majority of the forecasting uncertainty lies predominantly within the wind sector. If one wind farm gets it wrong there is a high probability that other farms will get it wrong; particularly when said farms employ the same MET data. It is therefore extremely likely that in periods characterised as (generation) over predicted, the SMP will have a tendency to rise as the demand grows for any excess capacity that is available from non wind generation plant. On a similar basis, the opposite should normally apply, but in high-wind/low-demand period the SMP could remain somewhat artificially high because of curtailment and or synchronous/ non-synchronous ratio being adhered to for system stability.

Furthermore if we consider the I-SEM, in an underpredicted period, the generator will only receive payment for the contracted amount. i.e. any excess generation will be lost revenue unless sold on the intraday market. Once again due to the excessively large wind penetration in Ireland and the fact that all wind predictions rely on the same input MET data, there is a high likelihood that this excess capacity may have to be sold at lower revenues than a previously contracted bid. This lower price represents what is effectively a loss of revenue for wind generators compared to the current set-up. As a consequence, increases in SMP are likely to occur as wind generators bid in higher capacities at higher unit costs in an attempt at levelling-out losses that might be incurred in over-generated periods. Anecdotally, in the Nord Pool Spot power market (largest in Europe), which reflects some of the proposals for the proposed I-SEM, the SMP was affected detrimentally with up to $20 \%$ price increases observed.

If we consider 3 scenarios for the year in question Feb '13 Jan '14 (as specified in Table 3) and benchmark them against the average SMP €64.32, an approximated change in revenue for the proposed I-SEM, in terms of the total wind generation, is suggested by Fig 7.

TABLE 3

SCENARIOS FOR FINANCIAL PENALTIES AS COMPARED TO THE AVERAGE ANNUAL SMP

\begin{tabular}{|l|l|l|l|l|}
\hline & benchmark & Scenario A & Scenario B & Scenario C \\
\hline SMP & 64.32 & $64.32(+0 \%)$ & $77.18(+10 \%)$ & $77.18(+20 \%)$ \\
\hline $\begin{array}{l}\text { Undergen } \\
\text { penalty } \\
\text { per MWh }\end{array}$ & $0 \%$ & $130 \%$ SMP & $120 \%$ SMP & $110 \%$ SMP \\
\hline $\begin{array}{l}\text { Overgen } \\
\text { Loss of } \\
\text { revenue }\end{array}$ & $0 \%$ & $85 \%$ SMP & $90 \%$ SMP & $95 \%$ SMP \\
\hline
\end{tabular}

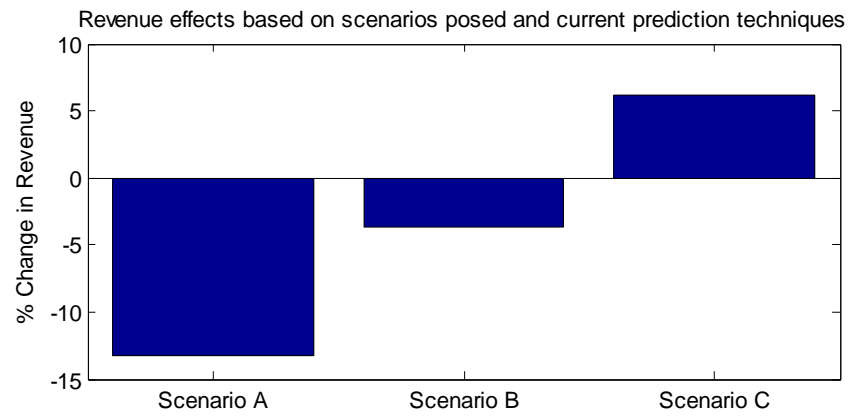

Fig. 7. Potential effects on revenue compared with the current SMP guaranteed scenario. Scenario A and B will result in a decrease in revenue for current Wind generators based on a 15 minute trading interval the current national prediction technology and the scenarios posed.

It must also be remembered that the cost of bidding whether automated via software or traded by a physical person is not included in the above scenarios and this also will have a tendency to increase the SMP.

\section{DISCUSSION}

The proposed changes in I-SEM will have an impact to the electricity trading environment. It is also evident that measures will need to be considered if the renewable energy mix currently in the Irish context can be sustained. It is also highly likely that the proposed changes will put pressure on the system generators, which results in an increased SMP as a consequence of the current inaccuracies within the wind power prediction sector. Any increase in the SMP would eventually be passed on to the consumer and this would not be the intended outcome of the I-SEM market.

That said there are currently some developments that are worth considering while awaiting I-SEM operational clarity. The following postulations are presented in this regard.

(i) The trading interval

The longer the trading interval the less this problem emerges as the error is based over a longer more definable period. The average of an error that fluctuates above and below zero will have a tendency to be closer to zero. 


\section{(ii) The intra-day balancing arrangement}

The intra-day balancing arrangement is currently not confirmed. For instance a balancing requirement could be done on a 24 hour period even though the trading interval could be based on shorter time intervals (currently 30 minutes).

\section{(iii) Pooling generators}

Another key way of minimising error is to accumulate a portfolio of generators and holistically average the positive and negative error into a singular error for a singular grouped bid.

\section{(iv) Time series modelling}

Traditional wind power forecasts are based on static statistical models rather than dynamic response models. Some work is currently underway at DIT in the consideration of ARMA and ARIMA financial forecasting models. This work is also coupled with the development of a transient response model that could be applied to a single turbine, wind farm or indeed on national wind power basis.

\section{(v) Site specific wind forecasting de-rating}

Using MET observations locally at wind farms will always present scope for error. Landscape heterogeneity and local morphology and topography will affect macro wind measurements being able to represent the wind regime prevalent at the wind farm. DIT through the Energy Resource Group are currently investigating the concept of de-rating macro MET forecasts to localised individual wind farms with the aid of custom developed high resolution anemometry devices.

\section{(vi) Short term storage and rapid response generation}

On-site, short term storage devices, are now becoming commercially viable in the form of inertia flywheels another option may be to have rapid response peaker devices such as diesel generators to make up a shortfall virtually instantly. While this may appear to be counter productive small generator sets (<2MVA) can be made to have an exceptionally fast response rate 10-30 seconds to virtually full load which is potentially far more environmentally friendly than reheating a thermal generation plant for a few hours (dependant on the technology) with virtually no output.

\section{CONCLUSION}

There is a general consensus that renewable energy, specifically wind energy, will play an important role in Ireland's future energy supply.

This paper sought to explore wind energy forecasting consistency by considering the error associated with the generation output of a small wind farm in comparison to the national forecasting as provided by Eirgrid, the Irish TSO. A number of analytical measures have been implemented to allow a better understanding of forecasting errors in relation to actual and predicted output of wind turbines.

The results illustrate in particular, the significant influence that sampling period has on the appreciation of generation capacity prediction error for both $\mathrm{WF}_{\mathrm{x}}$ and $\mathrm{WP}_{\mathrm{TSO}}$. From a financial perspective, and with such large public and private financial investment in the sector, every opportunity must be exhausted to potentially reduce the percentile errors.

There are significant challenging market changes being proposed for the Irish wind industry. When one considers the changes being proposed in a more defined ex anti market arrangement, errors, such as those observed here over the period of 2013-2014, could impact significantly the SMP for wind generation. It is also evident that further quantitative analysis is required to determine if top up technology is more viable than ex-anti trading based on.

\section{REFERENCES}

[1] A. McCrone, E. Usher, V. Sonntag-O'Brien, U. Moslener, and C. Grüning, "Global Trends in Renewable Energy Investment," Frankfurt School for Climate \& Sustainable Energy Finance,2014. [2] IWEA. (2015, 26th February, 2015)). Irish Wind Energy Investment Tops €350 Million in 2014 [on-line]. Available: http://www.iwea.com/index.cfm?page=viewnews\&id=131

[3] T. M. Letcher, Future Energy - Improved, Sustainable and Clean Options for our Planet: Oxford, 2008.

[4] H. Madsen, P. Pinson, G. Kariniotakis, H. Aa. Nielsen, and T. S. Nielsen, "A Protocol for Standardazing the performance evaluation of short term wind power prediction models," Wind Engineering, vol. 29, pp. 475-489.

[5] M. F. Bielecki, "Statistical Characterisation of Errors in Wind Power Forecasting," MSc., Northern Arizona University, 2010.

[6] CER and NIAUR, "Integrated Single Electricity Market (I-SEM) Non-technical summary," SEM-14-085d, 17 September 2014.

[7] E.U. New impetus for internal market: Agency for the Cooperation of Energy Regulators takes up operations in Slovenia [Online]. Available: http://europa.eu/rapid/press-release IP-11246_en.htm

[8] V. Di Cosmoa and M. Á. Lynch, "Competition and the Single Electricity Market: Which Lessons for Ireland?," Economic and Social Research Institute, 2015.

[9] European Commission, Directive 96/92/EC of the European Parliament and of the Council of 19 December 1996 concerning common rules for the internal market in electricity, 1996.

[10] P. K. Gorecki, "Ensuring compatibility of the all-island electricity system with the target model: Fitting a square peg into a round hole?," Energy Policy, vol. 52, pp. 677-688, 2013.

[11] CER and NIAUR, "Integrated Single Electricity Market (I-SEM): SEM Committee Decision on High Level Design," SEM-14085a, 17 September 2014.

[12] C. J. Willmott and K. Matsuura, "Advantages of the mean absolute error (MAE) over the root mean square error (RMSE) in assessing average model performance," Climate Research, vol. 30, pp. 79-82, 2005.

[13] T. Chai and R. R. Draxler, "Root mean square error (RMSE) or mean absolute error (MAE)? - Arguments against avoiding RMSE in the literature," Geoscientific Model Development, vol. 7, pp. 1247-1250, 2014. 